\title{
1. The value of bus rapid transit in urban spaces
}

Fiona Ferbrache

The extent of implementation and expansion of bus rapid transit (BRT) across the globe, typically since the 1970s, and particularly since the mid1990 s, is partial testimony to the positive valuation of BRT for many contemporary cities. BRT has been implemented in cities as a modern form of public transit for a variety of reasons that include facilitating accessibility, particularly in cities with high levels of motorization; improving mobility, often for lower-income residents; reducing carbon emissions; and stimulating urban growth and development through capital investment. More broadly, BRT has been linked to wider sustainability goals, urban planning and social equity initiatives (Paget-Seekins and Munoz 2016). Yet within and across different cities, BRT is valued (undervalued and contested) by a diversity of stakeholders in more complex, nuanced and multifaceted ways than these broad attributes initially suggest. Taking a grounded approach to BRT, this edited collection presents a compendium of BRT case studies from a range of cities, city-regions and countries across the globe, focusing on BRT's effects in their geographical contexts.

The principal aims of this book are twofold. First, individual chapters demonstrate how BRT is part of (mediating and mediated by) its urban environment (site and context), exploring such themes as BRT planning, financing, implementation, operation, performance, symbolic meaning and direct and indirect impacts. These chapters offer in-depth contributions drawing on empirical research from a diversity of urban spaces across several world regions: Asia, Australasia, Europe, North America, South Africa and South America. The contributions are written primarily by academics though also by non-academic sector experts from a range of countries. Second, together the chapters provide evidence of a host of ways in which BRT is valued (and undervalued) in urban spaces. Value refers here to that which is considered important, beneficial, useful and efficient (though this is not an exhaustive list of adjectives to help explain the term). As we will see, the variety and often complex values that emerge from these case studies hold significant implications 
for how they may be conceptualized and employed by academics and practitioners.

Thus, two important arguments run through this collection's focus on a spatial and more tentative consideration of valuation. First, that BRT is not initiated, planned or implemented on a neutral or blank canvas in cities, rather it is always already embedded in (and becomes part of) the materialities and immaterialities of places and people associated with these urban spaces. Second, that values need to be decodified from the triad of economic, social and environmental impacts that have become normalized by academics and practitioners in the assessment and valuation of BRT. Only then can values begin to be understood in relation to their complexity, nuance and interrelatedness. Alone and together, the chapters seek to inform and enhance understanding of BRT through grounded in-depth analysis, and it is hoped that this collection inspires further development of conceptual, methodological and empirical research on BRT.

To help set the scene further and expand some of these points, this opening chapter introduces BRT in its urban context, followed with discussion on transport valuation. Then, in a brief introduction to the case studies examined in each chapter, it points to some of the values that readers might discern from the various insights to BRT planning, implementation, design, operation and impacts that each chapter provides as individual contribution to this collection.

\section{INTRODUCING BRT}

There is generally consensus among academics that BRT usually refers to a bus-priority mode featuring high-capacity vehicles with rubber tyres, often operating on dedicated rights of way (that is, segregated corridors) with busway alignment, intersection priority, off-board payment and level boarding. BRT is an increasingly popular form of urban public transit in cities across the globe, though there are many variants of bus-priority systems including BRT Lite (more commonly associated with systems in North America) and buses with a higher level of service (BHLS) (more common in Europe), alongside BRT Full (Finn et al. 2010, Hidalgo and Gutierrez 2013'; see also Nelson and Deng, Chapter 6, this collection). Cervero (2013, p. 2) indicates that across a 'suite of high-quality, bus-based mobility options', 'what mainly distinguishes high-end [BRT Full] from low-end [BRT Lite] services is the presence of exclusive or dedicated rights-of-way for operating buses and more sustainable station platforms and boarding areas'. Table 1.1 indicates some of the differences between BRT Lite, BHLS and BRT Full though it is readily acknowledged that 
Table 1.1 Differences between BRT Lite, BHLS and BRT Full

\begin{tabular}{|c|c|c|c|}
\hline & BRT Lite & BHLS & BRT Full \\
\hline $\begin{array}{l}\text { Running } \\
\text { ways }\end{array}$ & $\begin{array}{l}\text { Mixed traffic; } \\
\text { limited exclusive } \\
\text { lanes }\end{array}$ & $\begin{array}{l}\text { Exclusive single } \\
\text { median or kerbside } \\
\text { lanes; certain } \\
\text { permeability of the } \\
\text { exclusive lanes }\end{array}$ & $\begin{array}{l}\text { Exclusive and } \\
\text { segregated transit-ways; } \\
\text { dual median lanes; } \\
\text { overtaking lanes }\end{array}$ \\
\hline $\begin{array}{l}\text { Stations/ } \\
\text { stops }\end{array}$ & $\begin{array}{l}\text { Stops, sometimes } \\
\text { with shelter, } \\
\text { seating, lighting } \\
\text { and passenger } \\
\text { information }\end{array}$ & $\begin{array}{l}\text { More substantial } \\
\text { stops and stations, } \\
\text { sometimes } \\
\text { with shelter, } \\
\text { seating, lighting } \\
\text { and passenger } \\
\text { information }\end{array}$ & $\begin{array}{l}\text { Large stations for } \\
\text { passenger comfort with } \\
\text { temperature control, } \\
\text { security and passenger } \\
\text { information systems; } \\
\text { sometimes transit } \\
\text { interchanges }\end{array}$ \\
\hline $\begin{array}{l}\text { Service } \\
\text { design }\end{array}$ & $\begin{array}{l}\text { More traditional } \\
\text { service provision; } \\
\text { medium capacity } \\
5000-15000 \\
\text { pphpd }{ }^{1} \text { average } \\
\text { speed } 18-23 \mathrm{~km} / \mathrm{h}\end{array}$ & $\begin{array}{l}\text { More advanced } \\
\text { service provision; } \\
\text { lower capacity } \\
500-2500+\text { pphpd; } \\
\text { average speed } \\
15-35 \mathrm{~km} / \mathrm{h}\end{array}$ & $\begin{array}{l}\text { Frequent services; } \\
\text { integrated with other } \\
\text { transport services; } \\
\text { higher capacity } \\
5000-45000 \text { pphpd; } \\
\text { average speed } 20-40 \\
\text { km/h }\end{array}$ \\
\hline $\begin{array}{l}\text { Fare } \\
\text { collection }\end{array}$ & $\begin{array}{l}\text { More traditional } \\
\text { methods such } \\
\text { as on-board } \\
\text { payment }\end{array}$ & $\begin{array}{l}\text { Off-board } \\
\text { pre-payment }\end{array}$ & $\begin{array}{l}\text { Off-board pre- } \\
\text { payment; smart cards }\end{array}$ \\
\hline $\begin{array}{l}\text { Additional } \\
\text { features }\end{array}$ & $\begin{array}{l}\text { More limited } \\
\text { technological } \\
\text { applications; } \\
\text { branding }\end{array}$ & $\begin{array}{l}\text { Multi-door } \\
\text { boarding; } \\
\text { branding }\end{array}$ & $\begin{array}{l}\text { Automated vehicle } \\
\text { location; passenger } \\
\text { information systems; } \\
\text { multi-door boarding; } \\
\text { branding; } \\
\text { Maximum speed } \\
60-70 \mathrm{~km} / \mathrm{h}\end{array}$ \\
\hline
\end{tabular}

Notes: ${ }^{1}$ pphpd: passengers per hour per direction

Source: revised from Cervero 2013, p. 2; Hidalgo and Gutierrez 2013

the boundaries between different bus-based modes are not clear cut and that any one system in a particular urban space may vary in its design and development from those in other cities. Furthermore, and as Finn et al. (2010) indicate, the concept of BRT heavy employed in North America appears highly similar to BHLS employed in Europe, indicating some further overlap between different forms rather than distinct categories. Thus, referring to a suite or spectrum of bus-priority systems rather than 
a hierarchy with clear boundaries between different designs appears to be a more realistic way of capturing overlap of the realities of design and function.

The presence of tailored systems to particular places calls for analysis of BRT in the specific sites and contexts in which systems develop. Grounded research 'from the bottom up' can help to interpret how BRT is mediated by its urban context and vice versa. Simultaneously, however, there is a risk that conceptualizing BRT in specific cities could misleadingly act to containerize the history, planning and performance of the system as isolated from discourses, policies and practices that stretch beyond imagined and politico-legal city boundaries. As many of the authors in this collection acknowledge, BRT 'here' may be very much influenced by BRT 'there' (see in particular Wood, Chapter 14, this volume), and thus a simultaneously grounded and open analysis is an approach that is valued through this collection.

Despite a range of BRT designs, the Institute for Transportation and Development Policy (ITDP), which designs and implements high-quality sustainable transport in cities, has been influential in its efforts to promote and protect the concept of BRT (Full) by establishing a quantifiable grading system known as BRT Standard. ${ }^{2}$ Based on assessment, BRT Standard may award cities a gold, silver or bronze rating for the quality of their BRT corridors. For ITDP, high-quality BRT systems, that is 'fast, comfortable, and cost-effective services at metro-level capacities', comprise the features mentioned above. Similar features are acknowledged by the Bus Rapid Transit Centre of Excellence (BRT CoE), a leading BRT research centre, which also adds that 'a high frequency bus service' (Paget-Seekins and Munoz 2016, p.2) is likely to have clear branding (see also Levinson et al. 2003) and stations with overtaking lanes (see also Lindau et al. 2014). Within a BRT network, however, there may be several bus-priority corridors covering a range of bus-only streets, exclusive lanes and mixed traffic lanes with no priority: not all corridors are able to meet best practice guidelines (i.e. BRT Standard), particularly where BRT is implemented into the existing urban fabric and where there may be little scope for new or redevelopment. BRT Standard grades BRT corridors rather than the entire network, though it is important that analysis acknowledges different scales at which BRT operates and impacts (as individual corridors, networks and as part of wider urban contexts (cities and city-regions), for example) as valuation of BRT changes as different scales and their associated spaces and actors come into play.

Among attempts to define BRT, academics and practitioners have drawn comparisons and contrasts with what it is not - namely other modes of transport such as conventional buses and rail-based systems. BRT is 
typically situated midway between these other modes, along a continuum that demonstrates an increasing level of segregation from conventional buses that do not run on separate road alignments, to light rail vehicles running on steel rails at higher speeds than bus systems (see Cervero 2013, p.25). This continuum also features a sliding scale of flexibility (of bus routes and services) to fixity or permanence (of rails with overhead wires or Alimentation par le Sol (ground power supplies); Levinson et al. 2003, Wright and Hook 2007), as well as generally increasing costs the closer one moves to the heavier and more permanent infrastructure of rail-based systems (Hensher 2007, Wright and Hook 2007). Beyond these quantifiable or tangible elements, the concept of 'emotional ideology' (Hensher 2016) serves to capture a more imagined, aesthetic and affective sense of BRT through which researchers acknowledge a perception that 'trains are sexy and buses are boring' (Hensher 2016, p. 289; see also Hensher et al. Chapter 5, this volume). Hodgson et al. (2013, p. 159) have argued that 'One way of generating ridership numbers for buses similar to light rail would be to make the bus look and feel like a tram', but some authors have argued that BRT should not be compared with, or expected to compete with, rail-based networks. Cervero (2013, p. 38), for example, argues that 'Rail versus bus is increasingly a false dichotomy': cities rarely have the opportunity to choose between one or other method, and BRT and light rail transit (LRT) are fundamentally different modes of public transport better suited to some cities than others. Vuchic (2005) supports noncomparison between BRT and other modes, partly to enable the design of a systematic system that is complementary to (rather than competing with) existing rail transport in the city (for example, BRT in Thailand's Bangkok, South Korea's Seoul and Mexico's Mexico City; as well as Metroplús in Medellín, Colombia (Chapter 13, this volume). Recognizing the value of BRT in its own right can help to provide an unbiased starting point for analysis and recognition of BRT of and for itself. However, in some cases, the decision to invest in BRT has been driven by comparisons (such as cost comparisons or emotive preferences) with LRT (in Ottawa, Canada (see Chapter 3, this volume) and Curitiba, Brazil, for example). BRT, then, cannot be entirely isolated from existing and potential modes of urban transport infrastructure, and the chapters here demonstrate this well.

BRT systems are now found across six continents, all of which feature in this collection and are said to have spread from (what is widely recognized as) its origins in Curitiba, Brazil (1970s) (Levinson et al. 2003, Global BRTData 2016, Lindau et al. 2016; for consideration of alternative BRT origins see Vergel-Tovar and Camargo, Chapter 11, this volume). A growing BRT academic and grey literature provides evidence of many successful and effective systems, not only in terms of achieving a certain level 
of BRT Standard (ITDP) but also in terms of assessing how well different examples meet their main objectives (Babalik-Sutcliffe and Cengiz 2015) generally, though not exclusively, linked to improving accessibility and mobility (particularly in cities with increasing population sizes and traffic congestion), tackling urban pollution and reconstructing the wider urban environment. Furthermore, investment in BRT can help to boost a city's image and prestige (Paget-Seekins 2015). Despite recognized successes, BRT evolves in a dynamic context where the urban environment constantly changes and this means that BRT must adapt to retain its value to remain competitive and successful. As a result, and in spite of this, challenges persist for BRT and, in some urban spaces, BRT has been discontinued and wholly or partially substituted with LRT (for example in Delhi, India; Essen, Germany and Edinburgh, UK; see Hass-Klau et al. 2003).

A recent and significant contribution to BRT literature is the collection edited by Munoz and Paget-Seekins (2016), based on the first five years of research from the BRT CoE. It showcases the excellent interdisciplinary and international research projects being carried out by the CoE to support practical application of BRT, and highlights 'the promise of BRT' (p. 1) to restructure public transport and urban spaces in sustainable ways, particularly for developing cities. Each chapter raises a critical challenge to the potential of BRT in relation to institutional relationships, operations and design or the broader urban context (including public space, passengers, transit-oriented development and other transport modes). The chapters in this edited collection complement and expand upon the insight to BRT's challenges and potential in Munoz and Paget-Seekins (2016). While some researchers have written for both collections, and both books situate BRT in specific urban contexts, this collection has greater focus on the broader urban context in which BRT is implemented. Furthermore, it draws on other valuable research taking place outside of the BRT CoE with examples from cities in what are typically referred to as more developed countries as well as cities in typically less developed countries.

Both edited collections also support the growth of BRT published literature, including journal papers, working papers, government and nongovernment reports, which provide valuable insight to the field of BRT, transport studies and urban planning, as well as broader fields dealing with sustainability, housing and health, for example. Existing BRT literature provides valuable critical insight demonstrating the strengths and limitations of BRT. By way of example, Bogotás TransMilenio, a gold standard system, has been widely presented as a success - Bogotá's 'jewel in the crown of recent transport reforms' (Gilbert 2008, p. 258) - and a model promoted to and revered by cities elsewhere (Gilbert 2008, Wood 2015). Gilbert's evaluation of Bogotá is invaluable, demonstrating that Bogotá's 
success is strongly linked to achieving mobility improvements for some of the city's lower-income inhabitants. However, Gilbert suggests that more broadly, Bogotá is not a strong example of integrated urban planning that has been able to foster economic growth in the city. What this example demonstrates, among other things, is that there are many components to, or impacts of BRT that may go beyond its original design and rationale but which are part of the evolving cityscape (see Vergel-Tovar and Camargo, Chapter 11, this volume). There are also, within cities, multiple different stakeholders (urban planners, transport investors, business owners, residents, workers from low-high-income sectors and unemployed, to name a few) who value or experience BRT and its impacts differently: what may be valued as a strength or benefit to one individual may be a disadvantage to another, just as an economic impact to a business owner may have a social as well as economic impact for the employee. These differing experiences of BRT can cause contestation or conflict between stakeholders. This complexity and potential conflict appears to be overlooked in much existing research for impacts are primarily discussed as beneficial enhancements. While such perspectives convey something important, they do not convey the full picture. To develop a more critical insight will likely require more qualitative and mixed-methods research, more holistic forms of analysis as well as innovative modelling techniques. Essentially, we also need to examine more critically what is meant by value.

\section{VALUING BRT}

The ways in which BRT has been valued - considered to be important, beneficial, useful and efficient by a range of different stakeholders unfold through all stages of BRT development from the conception of the idea through planning and implementation to the way BRT performs and impacts in a dynamic urban environment. Values may thus emerge, disappear and alter through time, as well as space. In transport research more broadly, a range of qualitative and quantitative methods have been employed by academics and practitioners to classify, assess and predict value, though one of the most prominent methods has been benefit-cost analysis which is based upon, and plays a role in normalizing classification of values as economic, social or environmental (Mackie and Nellthorp 2001). More often than not, these categories are treated as distinct from one another even though wider transport literature has recognized overlap between them (see for example Jones and Lucas 2012).

Valuation of BRT has largely followed this pattern, as identified in literature reviews by Deng and Nelson (2011), Stokenberga (2014) 
and Venter et al. (2017). The literature also includes analysis based on separation of direct transport impacts (travel costs, journey times and patronage, for example) and non-transport impacts (broader effects on the urban economy, environment and people, for example), as reflected in the wider transport literature (Knowles 1992, Banister and ThurstainGoodwin 2011). Non-transport impacts are often also referred to as wider impacts/benefits and while these impacts are often framed by neoliberal capitalist perspectives (including some social and environmental impacts), not all are valued in monetary terms, though quantification is a key device in evaluative techniques.

By following established techniques of valuation, analysis of BRT risks generating gaps in understanding, including the recognition and acknowledgement of impact limitations alongside benefits, and of connections between the analytical discreteness of categories. By way of example, a rise in land and property values in proximity to transit corridors, stops and stations is often presented as a positive impact of transport infrastructure. While this may be a positive impact for the property owner who could potentially secure a profit by selling or raising the rental on the property, the individual paying for this may perceive the increase more negatively. Rising property prices can lead to displacement of lower-income residents from city centre locations to city outskirts where transit access, as well as access to jobs or services, may be more difficult, thus impacting on economic and social wellbeing (see Grengs 2005, for example). This significantly impacts the way in which value is associated with BRT by such stakeholder groups. As such, comprehensive analysis is required to understand the experiences and opinions of a diversity of stakeholders, not only to develop a more nuanced understanding of the way in which values may be contested between actors, but also to provide a lens to some of the power relationships and social (in)equalities that can form in and around BRT (Venter et al. 2017). Questions relating to what is perceived or experienced as positive or negative, and for whom, need to be raised much more frequently to approach value in a critical way.

Hensher et al. argue (Chapter 8, p. 124, this volume) that

What is needed is a recognition of the value of including many possible solutions into the assessment mix right from the beginning, and having the ability to assess the relative merits of many criteria, not just patronage, but the broader considerations such as impact on the local (and maybe beyond) economy as well as the environment and wellbeing of society.

I would go further than this. Not only should research seek to engage critically with heterogeneous stakeholders and their multiple and often conflicting views and experiences, but a more nuanced analysis of the effects 
of BRT (beyond discrete classification) may help to capture how value is much more complex, multifaceted and interconnected than the broad categories of economic, environmental and social suggest. The chapters in this book are not specifically written to do this, their individual value emerges in the rich detail and contextualization to understand BRT in the cities in which it develops, and to provide detailed insight on different BRT effects. Together, however, the contributions provide a range of evidence on a host of values that provide more holistic insight than economic, social and environmental classifications allow for. A brief consideration of some of the values that readers may encounter in the following chapters is given below and returned to again in the conclusion.

The first three contributions to this collection provide case studies of BRT as it has been planned, implemented and operated in three different cities. Chapter 2 focuses on Adelaide's O-Bahn network in Australia, which opened in 1989. Direct value is assigned to BRT in this chapter in terms of patronage, accessibility and noise levels. Indirect value associated with the system can be identified in terms of landscaping and visual aesthetics, as well as ecology impacts in conjunction with a linear park that was constructed as part of the BRT planning along the transit.

Chapters 3 and 4 provide insight to BRT service provision in the Ottawa-Gatineau region of Canada (Chapter 3) and Auckland, New Zealand (Chapter 4). These two chapters conceptualize BRT as an ongoing project that continues to adapt and develop alongside other transport and urban planning initiatives. In both examples, it is the service that is given attention, providing insight on how it is valued in these cities. For example, the Auckland Northern Busway demonstrates the value attached to a high-quality and frequent BRT service aimed at reducing travel times and improving reliability to compete with road transport. Projections on future values of BRT are also examined in both.

Drivers of community preferences for BRT (relative to LRT) are examined in Chapter 5 across five countries: Australia, France, Portugal, the United Kingdom and the United States. The findings build upon an emotional bias against BRT, capturing perceived values and some of the variables that may influence them. This chapter explores a range of values as well as where and for whom they hold significance.

Chapter 6 examines the growth of BRT in China, demonstrating the way it is valued by planners and decision-making stakeholders for the speed with which it can be implemented at relatively lower cost than other forms of quality public transit. This chapter therefore reinforces some of the more typical values associated with BRT relative to rail-based modes. In addition, the authors consider some of the limitations of BRT in China, demonstrating what is valued in negative terms in this context. 
The range of values broadens from Chapter 7 which charts the planning, implementation, design, operation and impacts of Ahmedabad's BRT. In addition to direct values, this chapter reveals the spatial value of BRT to the city, its symbolic value in terms of branding and effort towards social inclusion through naming the system 'Janmarg', meaning 'people's way'. Other values are apparent relating to security and safety. In this chapter, we can also trace how different stakeholder values can produce tensions and management issues in relation to the way in which city space is used and regulated.

Chapter 8 introduces MetroScan_TI, a new web-based planning tool that is used to explore transport demand, economic appraisal and wider economic impacts of investment in transport. The tool is demonstrated through application to three different transport initiatives in Sydney, Australia, to enable comparisons between them. In terms of value, this tool offers the possibility of investigating a broad range of potential impacts that are now more commonly included in benefit-cost analyses; including factors grouped under social welfare values, environmental impacts, productivity factors and economic impacts.

Benefit-cost analysis is also taken up in Chapter 9 through the examination of three BRT systems in Great Britain: the Cambridgeshire Guided Busway, Fastway in West Sussex and the South East Hampshire BRT. Strengths and limitations are discussed in relation to each of these systems and alongside evidence of their assessment ranging from passenger surveys to ex ante and ex post evaluation. These different ways of measuring performance address a broad range of values across the direct-indirect impact spectrum.

Chapter 10 comprises a critical review of existing evidence of wider economic impacts organized on a geographical basis for Africa, Asia, Europe, North America, Oceania and South America. These economic impacts (and lack of) speak to broader agendas within some cities to bring about urban growth and development and to link transport investment into broader urban planning to enhance economic growth. Chapter 11 continues to focus on urban development with case studies of five Colombian cities that reveal some common patterns of urban growth in relation to commercial and residential developments. Key lessons including timing, planning coordination and management are drawn out for other cities to learn from.

Chapter 12 examines price and demand (based on apartment prices) for BRT proximity in Seoul, South Korea to determine welfare changes resulting from improved BRT accessibility. The perspective adopted in this chapter is of beneficial gain from a rise in financial value attached to properties relative to BRT.

Chapter 13 examines the contribution of Metroplús to the image of the 
Colombian city of Medellín, thus providing an example of less tangible values associated with BRT in relation to branding, social inclusion and the use of public space. The chapter emphasizes the need for decision making to involve diverse groups of stakeholders (planners and community, for example) in a more participatory process. In this way, the chapter demonstrates some of the tensions existing between different stakeholders in relation to access, rights and environmental features.

The final case study chapter explores BRT through the lens of a policy model, conceptualizing BRT as a product, policy and practice. Grounded in examples of BRT in South Africa, Chapter 14 unravels some of the politics that have driven development (replication) of BRT systems from other parts of the world, particularly from Bogotá. Multiple meanings associated with BRT emerge in this chapter, recognizing both material and immaterial values that extend beyond a city.

If read in sequence (and this is not a necessity of the book), the final chapter provides an appropriate lead into the conclusion which returns to some of the key considerations discussed here: spatiality and geographical embeddedness, valuation of BRT and future avenues for research.

\section{NOTES}

1. Alternative and additional definitions are to be found in the literature such as guided bus and busways (see for example Vuchic et al. 1994 and Hass-Klau et al. 2003) and BRT heavy (see Finn et al. 2010).

2. The ITDP works in cities of the United States, South America, Asia, Africa and Eastern Europe.

\section{REFERENCES}

Babalik-Sutcliffe, E. and E. Cengiz (2015), 'Bus rapid transit system in Istanbul: a success story or flawed planning decision?' Transport Reviews, 35, 792-813.

Banister, D. and M. Thurstain-Goodwin (2011), 'Quantification of the nontransport benefits resulting from rail investment'. Journal of Transport Geography, 19, 212-23.

Cervero, Robert (2013), Bus rapid transit (BRT): an efficient and competitive mode of public transport. Working paper 2013-01. Berkeley, CA: Institute of Urban and Regional Development.

Deng, T. and J.D. Nelson (2011), 'Recent developments in bus rapid transit: a review of the literature'. Transport Reviews, 31, 69-96.

Finn, B., O. Heddebaut and S. Rabuel (2010), Bus with a high level of service (BHLS): the European BRT concept. Transportation Research Board 89th Annual Meeting, Washington, DC. 
Gilbert, A. (2008). 'Bus rapid transit: is TransMilenio a miracle cure?' Transport Reviews, 28(4), 439-67.

Global BRTData (2016), Global BRT Data, accessed 21 June 2017 at www.brtdata. org

Grengs, J. (2005), 'The abandoned social goals of public transit in the neoliberal city of the USA'. City, 9, 51-66.

Hass-Klau, C., G. Crampton, C. Biereth and V. Deutsch (2003), Bus or Light Rail: Making the Right Choice: A Financial, Operational and Demand Comparison of Light Rail, Guided Buses, Busways and Bus Lanes. Brighton: Environmental and Transport Planning.

Hensher, D.A. (2007), 'Sustainable public transport systems: moving towards a value for money and network-based approach and away from blind commitment'. Transport Policy, 14, 98-102.

Hensher, D.A. (2016), 'Why is light rail starting to dominate bus rapid transit again?' Transport Reviews, 36, 289-92.

Hidalgo, D. and L. Gutierrez (2013), 'BRT and BHLS around the world: explosive growth, large positive impacts and many issues outstanding'. Research in Transportation Economics, 39, 8-13.

Hodgson, P., S. Potter, J. Warren and D. Gillingwater, D. (2013), 'Can bus really be the new tram?' Research in Transportation Economics, 39, 158-66.

Jones, P. and Lucas, K. (2012), 'The social consequences of transport decisionmaking: clarifying concepts, synthesising knowledge and assessing implications'. Journal of Transport Geography, 21, 4-16.

Knowles, Richard D. (1992), 'Light rail transport', in John Whitelegg (ed.), Traffic Congestion: Is There a Way Out? Hawes: Leading Edge Press, pp. 107-33.

Levinson, H., S. Zimmerman, J. Clinger, S. Rutherford, R.L. Smith, J. Cracknell and R. Soberman (2003), Bus Rapid Transit: Case Studies in Bus Rapid Transit, Vol. 1, TCRP Report 90. Washington, DC: Transportation Research Board of the National Academies.

Lindau, L.A., D. Hidalgo and A. de Almeida Lobo (2014), 'Barriers to planning and implementing bus rapid transit systems'. Research in Transportation Economics, 48, 9-15.

Lindau, L.A., Cristina A.M. da Silva, Guillermo P. Petzhold and Daniela Facchini (2016), 'Global overview of BRT and bus corridors', in Juan Carlos Munoz and Laural Paget-Seekins (eds), Restructuring Public Transport through Bus Rapid Transit: An International and Interdisciplinary Perspective. Bristol: Policy Press, pp. $15-30$.

Mackie, Peter and John Nellthorp (2001), 'Cost-benefit analysis in transport networks', in Kenneth. J. Button and David A. Hensher (eds), Handbook of Transport Systems and Traffic Control: Handbooks in Transport, Vol. 3. Oxford: Pergamon, pp. 143-74.

Munoz, John Carlos and Laural Paget-Seekins (eds) (2016), Restructuring Public Transport through Bus Rapid Transit. Bristol: Policy Press.

Paget-Seekins, L. (2015), 'Bus rapid transit as a neoliberal contradiction'. Journal of Transport Geography, 48, 115-20.

Paget-Seekins, L. and John Carlos Munoz (2016), 'The promise of BRT', in Juan Carlos Munoz and Laural Paget-Seekins (eds), Restructuring Public Transport through Bus Rapid Transit: An International and Interdisciplinary Perspective. Bristol: Policy Press, pp. 2-13.

Stokenberga, A. (2014), 'Does bus rapid transit influence urban land development 
and property values? A review of the literature'. Transport Reviews, 34(3), 276-96.

Venter, C., G. Jennings, D. Hidalgo and A.F.V. Pineda (2017), 'The equity impacts of bus rapid transit: a review of the evidence, and implications for sustainable transport'. International Journal of Sustainable Transportation, 12, 140-52.

Vuchic, V.R. (2005), 'Métros légers et liaisons rapides par autobus, modes concurrents ou complémentaires?' Transportation Public International, 5, 10-13.

Vuchic, V.R., E.C. Bruun, N.B. Krstanoski, Y.E. Shin, S. Kikuchi, P. Chakroborty and V. Perincherry (1994), The bus transit system: its underutilized potential. Report for the United States Department of Transportation Federal Transit Administration, Washington, DC.

Wood A. (2015), 'The politics of policy circulation: unpacking the relationship between South African and South American cities in the adoption of bus rapid transit'. Antipode, 47(4), 1062-79.

Wright, L. and W. Hook (2007), Bus Rapid Transit Planning Guide. New York: Institute for Transportation and Development Policy. 